\title{
Bipolaris spicifera isolates with unusual conidial germination pattern on sunflower from Iran
}

\author{
Arzanlou $\mathbf{M}^{1^{*}}$ and Khodaei $\mathbf{S}^{2}$ \\ ${ }^{1}$ Assistant Professor of Plant Pathology and Mycology, Plant Protection Department, Faculty of Agriculture, University \\ of Tabriz, PO Box: 5166614766, Iran. \\ ${ }^{2}$ MSc Student of Plant Pathology, Plant Protection Department, Faculty of Agriculture, University of Tabriz, PO Box: \\ 5166614766, Iran.
}

Arzanlou M, Khodaei S 2012 - Bipolaris spicifera isolates with unusual conidial germination pattern on sunflower from Iran. Plant Pathology \& Quarantine 2(1), 64-68, doi 10.5943/ppq/2/1/9

Bipolaris isolates with unusual conidial germination pattern were isolated from sunflower leaves in Northern Iran. Conidia germinated to form swollen germ tubes from both ends and swollen germ tubes underwent multiple branching soon after formation. The species was identified as Bipolaris spicifera based on phenotypic characteristics as well as sequence data from gpd and ITS-rDNA regions. Artificial inoculation of 4-week-old seedlings of sunflower under green house conditions induced chlorotic spots on sunflower leaves. This is first report on the occurrence of Bipolaris spicifera on sunflower in Iran. Our results on the unusual germination pattern of $B$. spicifera conidia, further stress the need for the implementation of molecular data for the identification of plant pathogenic Bipolaris species.

Key words - gpd - ITS - leaf spot - sunflower - unusual conidium germination pattern

\section{Article Information}

Received 1 May 2012

Accepted 4 May 2012

Published online 3 June 2012

*Corresponding author: Mahdi Arzanlou - e-mail - Arzanlou@ hotmail.com

\section{Introduction}

In a survey of leaf-infecting fungi in northern Iran, Bipolaris spicifera Shoemaker isolates were recovered from cultivated sunflower (Helianthus annuus L.). The genus Bipolaris was erected by Shoemaker to accommodate species formerly included in Helminthosporium Link (Tsuda \& Ueyama 1981). The genus is characterized by generally solitary, distoseptate conidia, sympodial proliferation of conidiophores, and bipolar germination of conidia (Alcorn 1983). Until now three Bipolaris species viz., B. spicifera (Bainier) Subram, B. sorokiniana (Sacc.) Shoemaker and B. zeicola (Stout) Shoemaker have been reported to occur on sunflower leaves or seeds (Chidambaram et al. 1973, Pandy \& Saharan 2005). Herein we document Bipolaris spicifera to occure on cultivated sunflower leaves in Iran and further discuss morphology and ecology of this species.

\section{Methods}

\section{Isolates and morphology}

Infected leaves of sunflower were collected during August-September 2010 from Salmas, West Azerbaijan, Iran. Fungi were isolated from leaf lesions following surface sterilization in $70 \%$ ethanol, and plating on potato carrot agar (PCA; $20 \mathrm{~g} \mathrm{~L}^{-1}$ potato, $20 \mathrm{~g}$ $\mathrm{L}^{-1}$ carrot, $20 \mathrm{~g} \mathrm{~L}^{-1}$ agar). To obtain pure cultures a mass of conidia were transferred to $2 \%$ malt extract agar (MEA, Fluka, Hamburg, Germany) plate containing $10 \mathrm{ml}$ distilled water, supplemented with $100 \mathrm{mg} / \mathrm{L}$ streptomycin sulphate and $100 \mathrm{mg} / \mathrm{L}$ ampicillin. The resulting spore suspension was streaked on MEA. Conidia were allowed to germinate, and single-spore transfers were made. The cultures 
were deposited in the living culture collection of Tabriz University (CCTU), Tabriz, Iran. Description of morphology was made based on 7-day cultures on PCA, exposed to $8 / 16 \mathrm{~h}$ of alternate cool white florescent light and darkness at room temperature. Three plates of PCA were produced for cultural and microscopic characterization. Microscopic structures were mounted in lactic acid for measurements. Thirty measurements were made for each microscopic element. Photographs were captured with a Leica camera system.

\section{Pathogenicity test}

Koch's postulates were conducted in the greenhouse on 4-week-old seedlings. A suspension of inoculum containing $10^{5}$ conidia $\mathrm{ml}^{-1}$ was prepared from 10-day-old cultures. Seedlings were sprayed to runoff with conidial suspension containing $0.04 \%$ of Tween 80, and control plants were inoculated with sterile water containing Tween 80 . The inoculated seedlings were given a $48 \mathrm{~h}$ dew period. The notation of results was made during 10 days after inoculation. Inoculated leaves were detached and cut into small pieces, surface sterilized, and plated on PCA plates for fungal re-isolation.

\section{DNA phylogeny}

DNA extraction was performed with the protocol of Moller et al. (1992). The 3' end of the 18S rRNA gene, ITS1, 5.8S rDNA, ITS2 and the 5' end of $28 \mathrm{~S}$ rRNA gene regions were amplified with primers ITS1 and ITS4 (White et al. 1990). PCR was performed on a GeneAmp PCR System 9700 (Applied Biosystems, Foster City, CA). Cycling conditions consisted of $5 \mathrm{~min}$ at $95^{\circ} \mathrm{C}$, followed by 36 cycles of $30 \mathrm{~s}$ at $94^{\circ} \mathrm{C}, 30 \mathrm{~s}$ at $52^{\circ} \mathrm{C}$ and $1 \mathrm{~min}$ at $72^{\circ} \mathrm{C}$, followed by one cycle of $7 \mathrm{~min}$ at $72^{\circ} \mathrm{C}$. Glyceraldehyde-3-phosphate dehydrogenase $(g p d)$ gene was amplified with gpd1 and gpd2 primers (Berbee et al. 1999). Amplification reaction mixture contained $1 \mathrm{X}$ PCR buffer, $1 \mathrm{mM} \mathrm{MgCl} 2,60 \mu \mathrm{l}$ of $1 \mathrm{mM}$ dNTPs, $0.2 \mathrm{pM}$ of each primer, $0.5 \mathrm{U}$ of Taq polymerase, $0.5 \mu \mathrm{l}$ DSMO, and 10-15 ng of fungal genomic DNA. The final reaction volume was adjusted to $12.5 \mu \mathrm{l}$ by adding sterile distilled water. The thermal cycling program consisted of a 5 min initial denaturation at $94^{\circ} \mathrm{C}$, which was followed by 40 cycles of $30 \mathrm{~s}$ denaturation at $94^{\circ} \mathrm{C}, 30 \mathrm{~s}$ primer annealing at $57^{\circ} \mathrm{C}$, and $30 \mathrm{~s}$ extension at $72^{\circ} \mathrm{C}$, and $7 \mathrm{~min}$ at $72^{\circ} \mathrm{C}$ for a final extension. DNA sequencing was performed using the BigDye Terminator v3.1 (Applied Biosystems, Foster City, CA) Cycle Sequencing Kits and analyzed on an ABI Prism 3700 (Applied Biosystems, Foster City, CA) according to the recommendation of the vendor. For the species identification, sequence similarity searches were performed for each of the sequences using Megablast search option at NCBI's GenBank nucleotide database

\section{Results}

\section{Morphological and cultural features}

Colonies (Fig. 2) expanding velvety, brownish grey, with olive green margins, flat, circular, entire, attaining a diam. of $7 \mathrm{~mm}$ after 7 days. Hyphae branched, septate, sub-hyaline to pale brown, 4-7 $\mu \mathrm{m}$ diam. Conidiophores arising singly, lateral or terminal, simple or rarely branched, septate, smooth-walled, straight or flexuous, repeatedly geniculate, mid brown, the upper fertile region up to $100 \mu \mathrm{m}$ long. Conidiogenous cells (Fig. 7) polytretic, integrated, terminal, sympodial, subcylindrical, cicatrized, with several (mostly 68) geniculation, dark brown. Conidia (Figs 3, 5-7) acrogenous, straight, sub-cylindrical, smooth walled, tapering towards paler and obtuse ends, $27-34 \times 9-11 \mu \mathrm{m}$, typically with 3 and rarely with 6 distosepta, juvenile conidia pale brown, becoming yellow-brown at maturity, hilum conspicuous, the first conidial septum median or sub-median, the second septum delimits basal cell, the third septum distal. Germination bipolar, basal germ tube semiaxial, apical germ tube axial, both germ tubes swelling and branching close to the conidium (Fig. 4).

\section{Pathogenicity test}

In field-grown crops, the fungus was associated with Alternaria leaf spot. Symptoms on inoculated leaves appeared 7 days after inoculation, and were characteristically small (up to $4 \mathrm{~mm}$ ), chlorotic spots, presumably due to toxin production (Fig. 1). The fungus was reisolated from the inoculated leaves. 


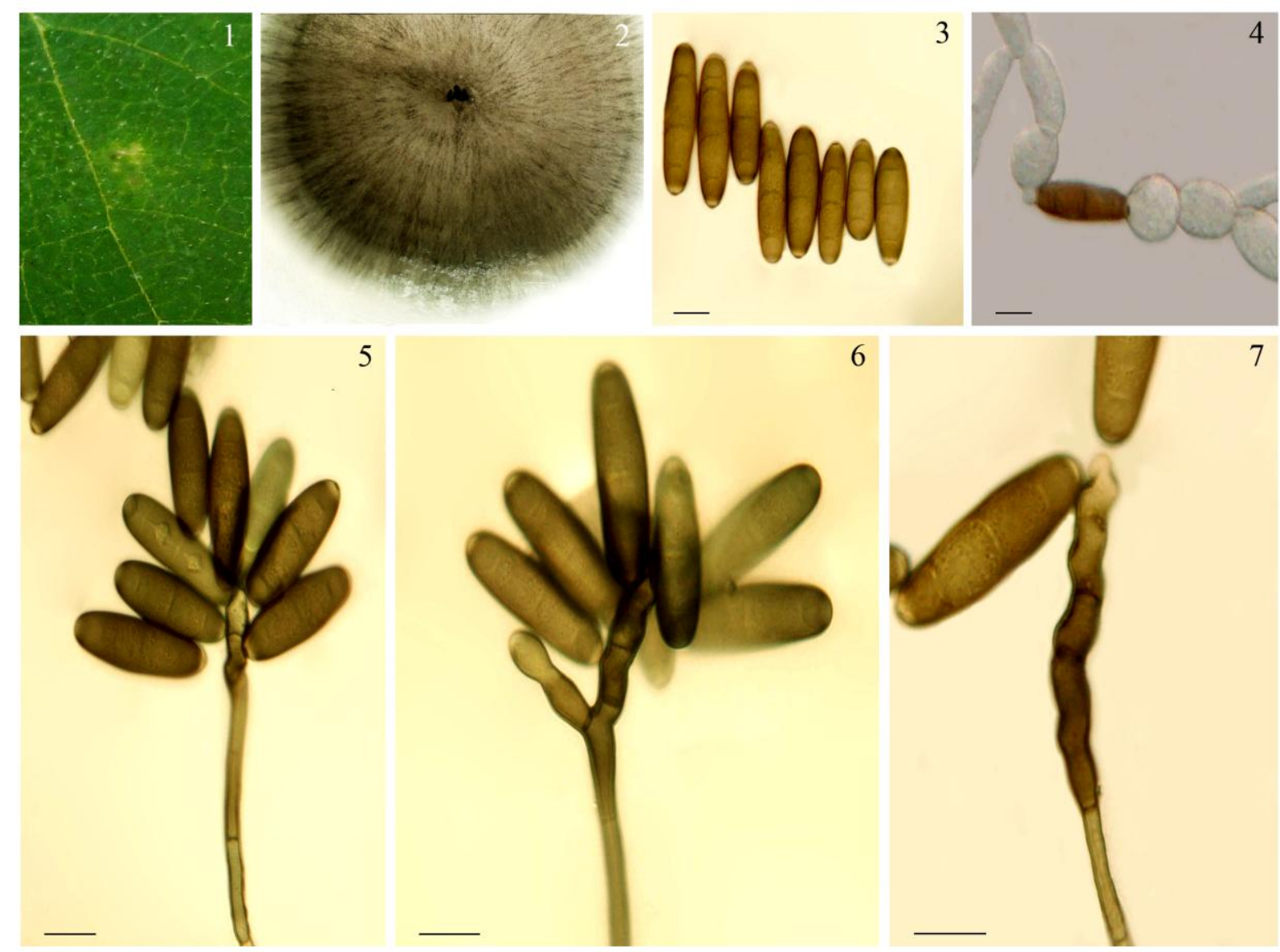

Figs 1-7 - Bipolaris spicifera. 1 Symptoms developed on in vitro inoculated sunflower leaves, seven days after inoculation. 2 7-day-old colony on PCA. 3 Conidia. 4 Germinated conidium. 5-7 Conidia and conidiophores. Bars $=10 \mu \mathrm{m}$.

\section{DNA phylogeny}

Sequence comparisons of ITS-rDNA region showed $100 \%$ identity with known $B$. spicifera gene sequences available in GenBank (GenBank Accession No. JX070077). There was no sequence data available for gpd gene of B. spicifera in GenBank; hence, the gpd sequence was compared with the sequence data set of Dr Hugo Madrid at CBS-Fungal Biodiversity Centre, Utrecht, The Netherlands. The gpd sequence generated in this study (GenBank Accession No. JX070078) was identical to those of B. spicifera.

\section{Discussion}

In 1959 Shoemaker originally proposed the generic name Bipolaris to accommodate some species of Helminthosporium which, unlike Helminthosporium spp., have interminate conidiophores (Goh et al. 1998). The genus is allied with Drechslera, Exserohilum and Curvularia which are, respectively, associated with Pyrenophora, Setosphaeria and Cochliobolus teleomorphs (Goh et al. 1998,
Zhang \& Berbee 2001). The asexual states of these fungi can be separated based on the following taxonomic criteria: conidium shape, hilum morphology, origin of the basal germ tube and its relative position to the conidial axis, conidial septum sequence, and the delimitation of the basal cell (Alcorn 1983).

Bipolaris and other allied genera encompass considerable morphological similarities. Recently, molecular studies have supported these groups as monophyletic lineages. For instance, phylogenetic relationships among Cochliobolus and related species of Pyrenophora and Setosphaeria have been established based on analysis of the internal transcribed spacer (ITS) and glyceraldehyde-3-phosphate dehydrogenase (gpd) data. This analysis clearly delimited these three genera. Two genera composed a monophyletic SetosphaeriaCochliobolus clade with Pyrenophora as the sister taxon (Berbee et al. 1999).

Until now over 100 species of Bipolaris have been described (Brecht 2005, Crous et al. 2004). The present species is similar to $B$. 
spicifera in all essential features, but it differs from the type specimen of this fungus in conidial germination pattern; in our isolates conidia germinate to form swollen germ tubes from both ends and swollen germ tube undergo multiple branching soon after formation. The phenomenon of dimorphic germination in $B$. spicifera suggests that other factors may also operate in mediating this response. For example, it has been suggested that conidial germination type in B. oryzae (Breda de Haan) Shoemaker is culture medium dependent (Dela Paz et al. 2006). However, a phylogeny inferred based on ITS sequence data placed all of $B$. oryzae isolates with different germination pattern as a single clade (Dela Paz et al. 2006). Our results on the unusual germination pattern of $B$. spicifera further stress the need for the implementation of molecular data for identification of plant pathogenic fungi, especially Bipolaris species. We compared our isolates with the other morphologically and phylogenticaly similar species in this genus such as $B$. australiensis (Ellis) Tsuda \& Ueyama. These two species can be differentiated based on conidial dimensions (Tsuda and Ueyama 1981). B. spicifera is probably heterothallic as no teleomorph was formed in monosporic cultures.

Several species of the genus Bipolaris have been reported on different plant species in Iran (Ershad 2009). A number of species such as B. oryzae, B. sorkiniana (Sacc.) Shoemaker and B. maydis (Nisik. \& Miyake) Shoemaker are responsible for economically important diseases on agricultural crops such as rice, barley and maize, respectively. B. spicifera has already been isolated from over 70 host plants, from air and soil (Ahmadpour et al. 2011). Furthermore, the fungus is being recognized with increasing frequency as a causal agent of human disease (Padhye et al. 1986, Eghtedari $\&$ Pakshir 2006). To the best of our knowledge, this is the first report of sunflower leaf colonisation by B. spicifera in Iran.

\section{Acknowledgements}

The authors would like to thank the Research Deputy of the University of Tabriz and the Studienstiftung Mykologie for financial support.

\section{References}

Ahmadpour A, Donyadoost-Chelan M, Heidarian Z, Javan-Nikkhah M. 2011 New species of Bipolaris and Curvularia on grass species in Iran. Rostaniha 12(1), 39-49.

Alcorn JL. 1983 - Generic concepts in Drechslera, Bipolaris and Exserohilum. Mycotaxon 17, 1-86.

Berbee ML, Pirseyedi M, Hubbard S. 1999 Cochliobolus phylogenetics and the origin of known, highly virulent pathogens, inferred from ITS and glyceroldehyde-3-phosphate dehydrogenase gene sequences. Mycotaxon 91, 964-977.

Brecht MO. 2005 - Ecology and pathogenicity of Bipolaris spp. and Curvularia spp. associated with decline of ultradwarf bermudagrass golf putting greens in Florida, USA. PhD Dissertation, University of Florida.

Chidambaram P, Mathur SB, Neergaard P. 1973 - Identification of seed-borne Drechslera species. Friesia 10, 165-207.

Crous PW, Gams W, Stalpers JA, Robert V, Stegehuis G. 2004 - MycoBank: an online initiative to launch mycology into the 21st century. Studies in Mycology 50, 19-22.

Dela Paz MAG, Goodwin PH, Raymundo AK, Ardales EY, Vera Cruz CM. 2006 Phylogenetic analysis based on ITS sequences and conditions affecting the type of conidial germination of Bipolaris oryzae. Plant Pathology 55, 756-765.

Eghtedari M, Pakshir K. 2006 - Asyptomatic fungal cyst of conjunctiva caused by Bipolaris spicifera. Iranian Journal of Medical Sciences 31(1), 56-58.

Ershad D, 2009 - Fungi of Iran. 3rd edition, Iranian Research Institution of Plant Protection, $531 \mathrm{p}$.

Goh TK, Hyde KD, Lee DKL. 1998 - Generic distinction in the Helminthosporiumcomplex based on restriction analysis of the nuclear ribosomal RNA gene. Fungal Diversity 1, 85-107.

Moller EM, Bahnweg G, Geiger HH. 1992- A simple and efficient protocol for isolation of high molecular weight DNA from filamentous fungi, fruit bodies, and 
Plant Pathology \& Quarantine Doi 10.5943/ppq/2/1/9

infected plant tissues. Nuclear Acid Research 20, 6115-6116.

Padhye AA, Ajello L, Wieden MA, Steinbronn

KK. 1986 - Phaeohyphomycosis of the nasal sinuses caused by a new species of Exserohilum. Journal of Clinical Microbiology 24(2), 245-249.

Pandy RN, Saharan GS. 2005 - Facultative fungal disease of sunflower. In: Disease of oilseed crops (eds GS Saharan, N Mehta, MS Sangwan). Indus Publishing Company, New Delhi, India 373-459.

Tsuda M, Ueyama A. 1981 Pseudocochliobolus australiensis, the ascigerous state of Bipolaris australiensis. Mycologia 73, 88-96.

White TJ, Bruns TD, Lee SB, Taylor JW. 1990 - Amplification and sequencing of fungal ribosomal RNA genes for phylogenetics. In: PCR-Protocols and Applications - A Laboratory Manual (eds $\mathrm{N}$ Innis, D Gelfand, J Sninsky, TC White). Academic Press, New York 315-322.

Zhang G, Berbee, ML. 2001 - Pyrenophora phylogenetics inferred from ITS and glyceradehyde-3-phosphate dehydrogenase gene sequences. Mycologia 93, 1048-1063. 